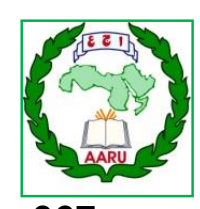

دراسة اقتصادية للقدرة التنافسية لمحصول الطماطم في مصر

$$
\begin{aligned}
& \text { السيد عبد العظيم الخشن" الخئ } \\
& \text { المعهد العالي للتعاون الزراعي - شبرا الخيمة - القاهرة - مصر الفئ }
\end{aligned}
$$

*Corresponding author: elkhishinss@gmail.com

Received 15 April, 2020

Accepted 16 August, 2020

التتاقص والتزايد حتى وصل في آخر الفترة لحوالي

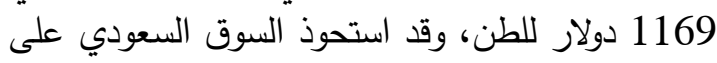

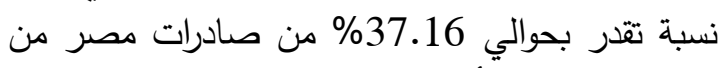

$$
\text { الطماطم الطازجة أو المبردة . }
$$

كما أوضح البحث وجود ميزة نسبية ظاهرة لصادرات الطبرة الطبات

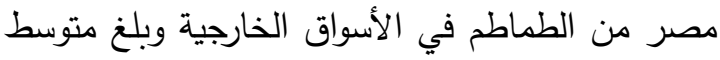

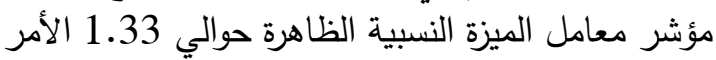

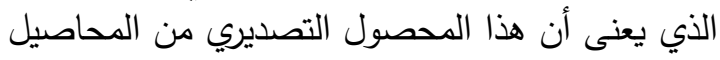

الهامة التي تتافس بثدة في الأسواق العالمية.

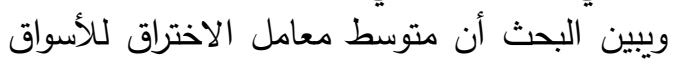
محل الدراسة للطماطم ضعيف وأن هنالك زيادة طفيفة في الإني

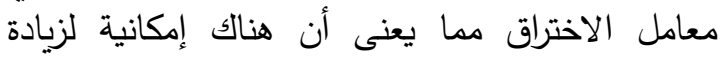

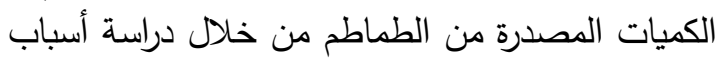

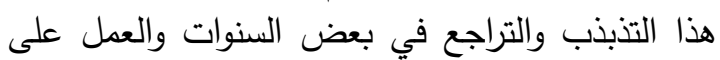

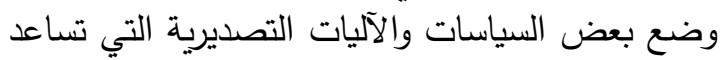
على زيادة الفرص التتافسية وتسهيل اختراق الأسواق التهات الدولية . الدي

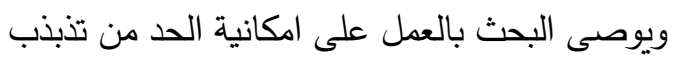

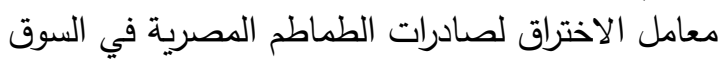

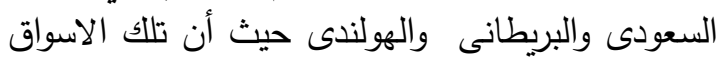

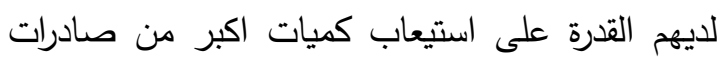
الطماطم المصرية.

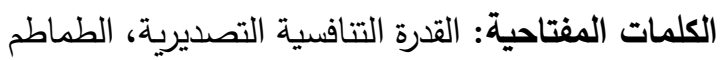

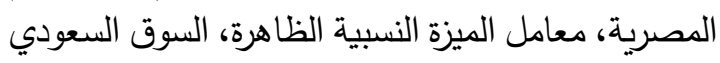

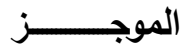

تعاني صادرات الخضر المصرية من تراجع التتافسية

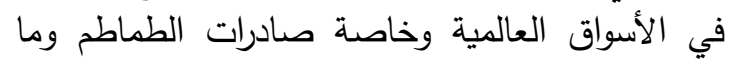
تعانيه من زيادة حدة المنافسة في اختراق الاسواق الاقداق

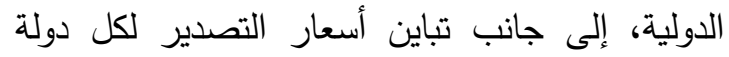

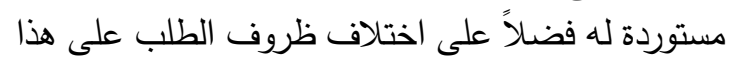

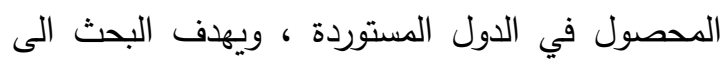

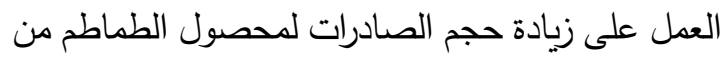
خلال التعرف على أهم مؤشرات القدرة التتافسية في التي الأسواق العالمية لصادرات هذا المحصول، هئرات حيث يتبين

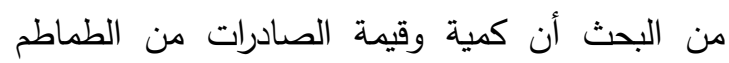

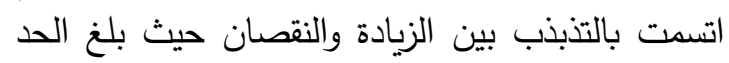

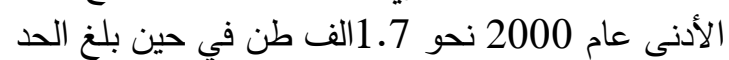
الأقصى حوالي 74.8 الف طن عام 2013 ثم أخذت فئ في التذبذب حتى نهاية الفترة عام 2018 حيث بلغ لفت الكمية المصدرة حوالي 41.8 الف طن الفي وأن القيمة

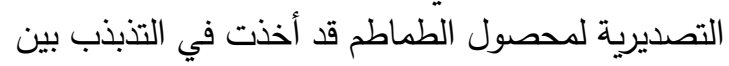

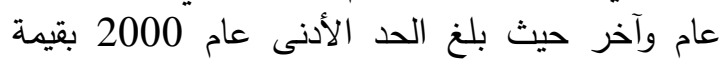
تصديرية بلغت حوالي 454 ألف دولار في حين الأن بلغ الحد

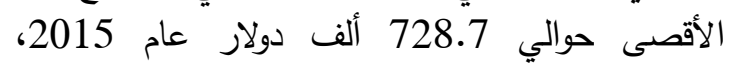
وتتاقصت في نهاية الفترة حيث وصلت لحوالي 488.6

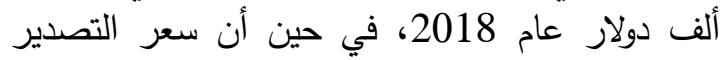
لمحصول الطماطم أخذ في التذبذب من فين أن عام 2000 حتى عام 2007 ووصل للقيمة الأقصى في عام 2017 لفي حيث بلغ حوالي 1513 دولار للطن وأخذ بعد ذلك في عام 
المركز التتافسي والقديرة التتافسية في أهم الأسواق

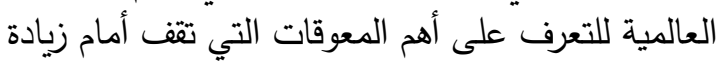

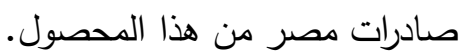

\section{الطريقة البحثية ومصادر البيانات:}

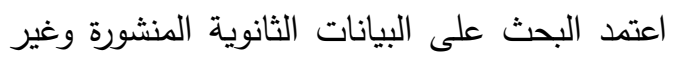

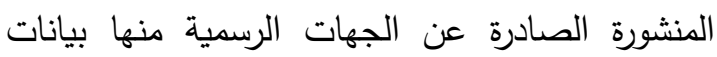

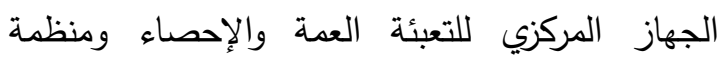

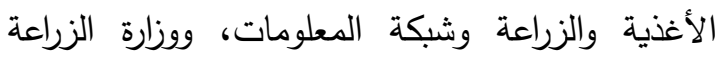

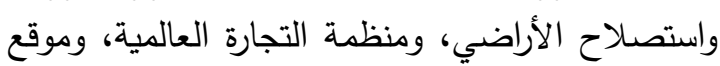
البنك الدولي على شبكة المعلومات.

الإطار النظري

بالإضافة إلى بعض البحوث والدراسات ذات الصلة

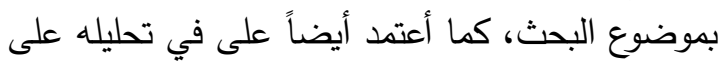

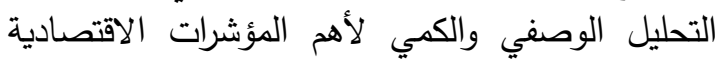

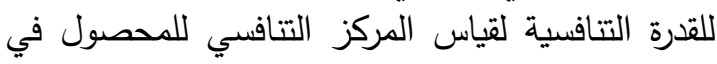
الأسواق العالمية منها:

\section{1-مؤشر الميزة النسبية الظاهرة}

\section{Revealed Comparative Advantage}

وهو عبارة عن النسبة بين الأهمية النسبية لصادرات

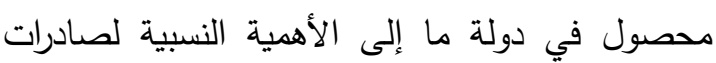

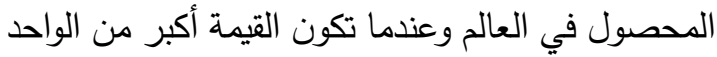

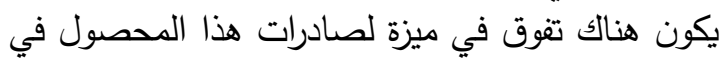
هذه الدولة ويمكن الحصول هيلية تعن من المعادلة التالية:

$$
\operatorname{RCA} j=\begin{array}{ccc}
\text { Xje } & & \text { Xjw } \\
---- & \div & - \\
\hdashline a e & & \text { Xaw }
\end{array}
$$

حيث تمثل: RCA الميزة النسبية الظاهرة. قيمة صادرات الدولة (e) من السلعة (j) إلى الى العالم. Xja Xae

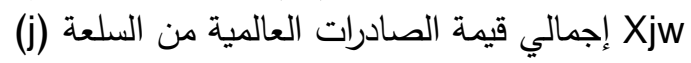
Xaw

\section{مقدمة}

تلعب الصادرات المصرية بصفة عامة والزراعية منها

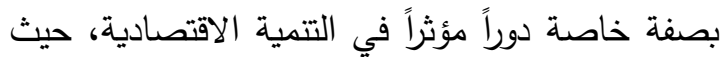

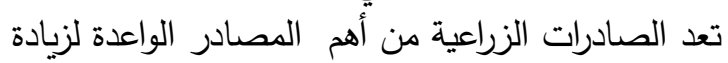

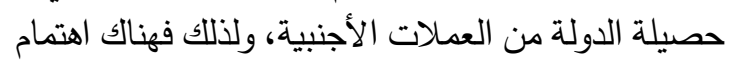

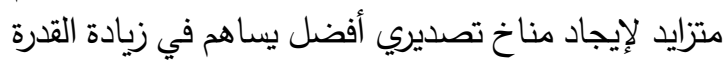

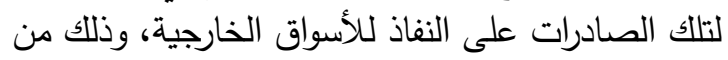
خلال زيادة قدرتها التتافسية حتى يمكن تخفيض الفاذ لانوات العزي في الميزان التجاري والذى بلغ حوالى 2.97 مليار دولار

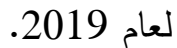

وتعتبر الطماطم من المحاصيل الخضرية التى تتوافر

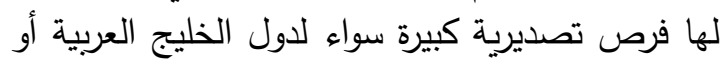

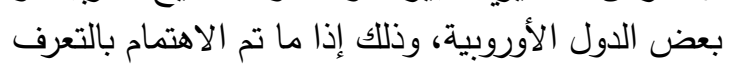

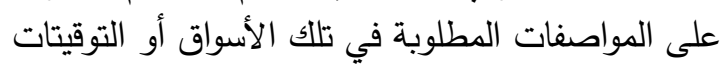
المناسبة بما يساعد على تحسين الميزان التجاري الزراعي التي التي

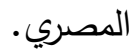

\section{مشكلة البحث}

تكمن مشكلة البحث في زيادة حدة المنافسة التي يوجها محصول الطماطح في اختراق الاسواق الدولية

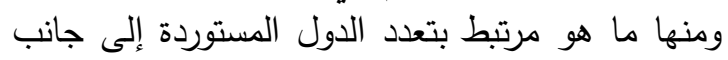
اختلاف أسعار التصدير لكل دولة مستوردة لـأله فضلاً

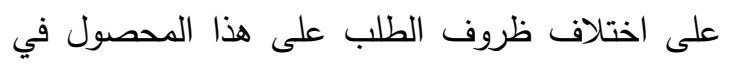

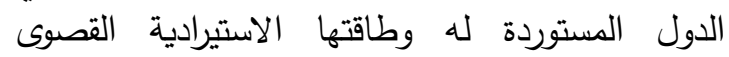

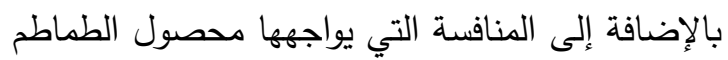
في الأسواق الخارجية وأثر ذلك على الكميات التصافي المصدرة

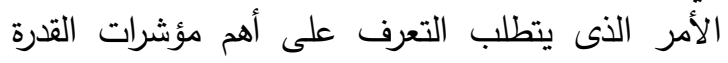
التتافسية في الأسواق العالمية لصادرات هذه المحاصيل.

\section{هدف البحث}

يهدف البحث الى العمل على زيادة حجم الصادرات

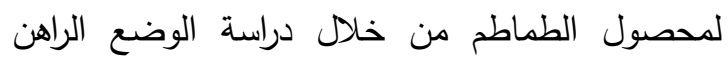

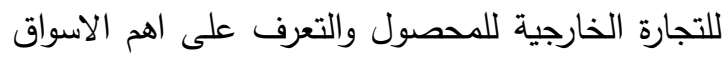

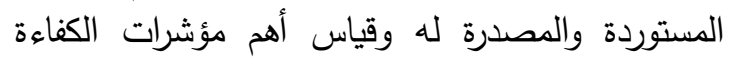

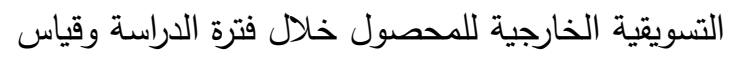


2- تقدير الوضح النسبى لسعر مصر بالنسبة للدول المنافسة من خلال المعادلة الآتية:

$$
R A_{j}=\frac{P A_{j}-P A_{\min }}{P A_{\max }-P A_{\min }}
$$

حيث أن:

PAj

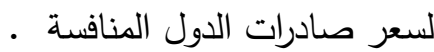
PAmax . PAmin

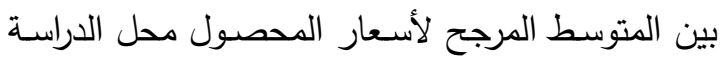

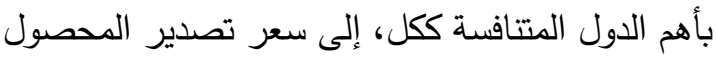

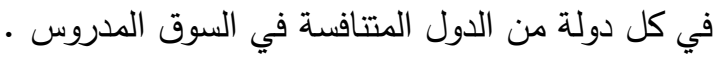

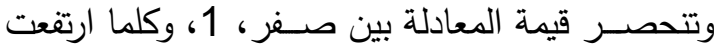

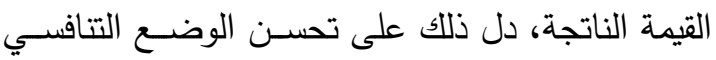
السعري للصادرات المصرية، والعكس صحيح.

$$
\text { نتائج البحث ومناقثتها }
$$

أولاً: تطور كمية وقيمة وسعر التصدير الطماطم المصرية خلال الفترة (2000 -2018) يتبين من البيانات الواردة بالجدول رقم (1) والذى

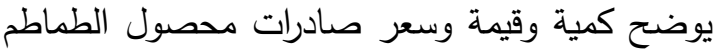
خلال أن كمية الصادرات من الطماطم تتباين بين الزيادة الطياد

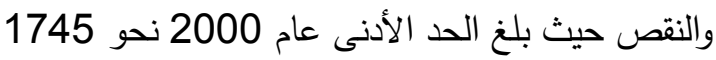

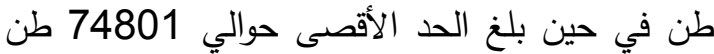
عام 2013 ثم أخذت في التناقص والتزايد حتى نهاية الفترة عام 2017 حيث بلغت الكمية المصدرة حوالي 41791 طن، وتوضح معادلة الاتجاه الزمني العام العيام الواردة بالجدول رقم (2) الزيادة السنوية المعنوية إحصائياً

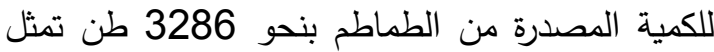
نحو 12.3\% من متوسط الكمية الدصدر لفترة الدراسة التحن

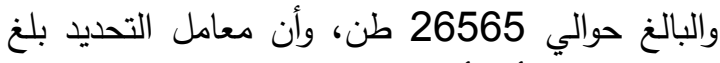
حوالي 0.53 أي أن 53\% من التغيرات الحادثة في التي

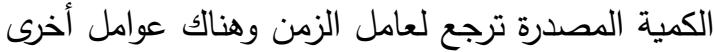

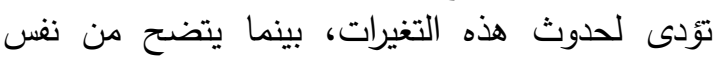

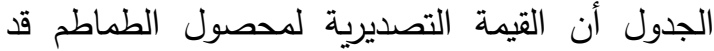
أخذت في التزايد حتى عام 2015 والتناقص تدريجيا

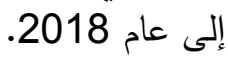

2-معدل اخترلق السوق

\section{Market Penetration Rate}

يعرف معدل اختراق السوق، بأنه النسبة بين واردات

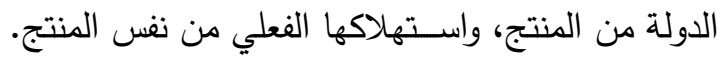
ويمكن حسابه من المعادلة التالية:

$$
M P R_{i j}=\frac{I_{i j}}{Q_{i j}+I_{i j}-E_{i j}}
$$

$$
\text { حيث أن : }
$$

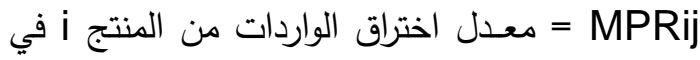

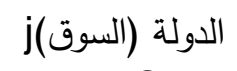

$$
\text { i إنتاج الدولة j من المنتج (المحصول) = Qj }
$$

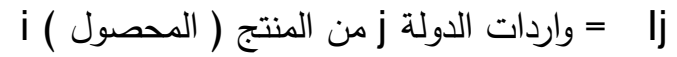

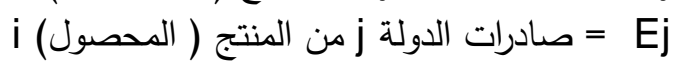

مؤشر التنافسية السعرية

\section{The Price Competitiveness Indicator}

ويتم حساب هذا المؤشر من خلال

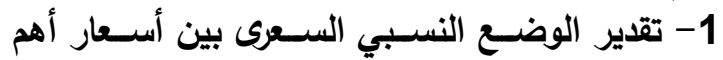

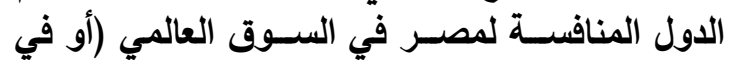

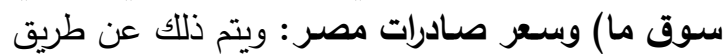

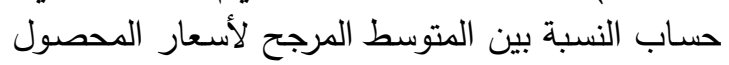

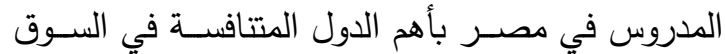

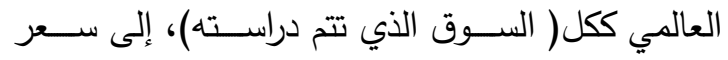

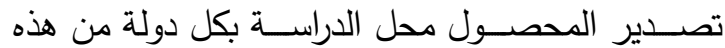
الدول ، وذلك باستخدام المعادلة التالية :

$$
P A_{j}=\frac{P_{c}}{P_{e}}
$$

PAj

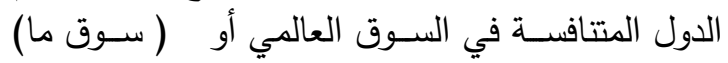

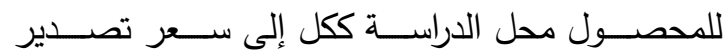

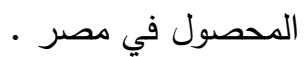
PC : المتوسط المرجح لأسعار تصدير المحصول : PC في أهم الدول المتنافسة ككل. Pe 
وقد بلغ معامل التحديد للقيمة المصدرة نحو 0.68

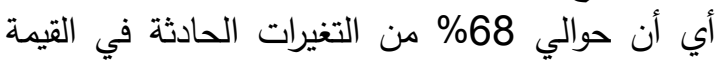

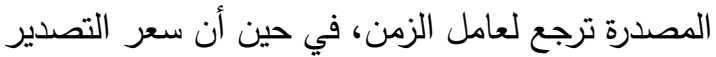

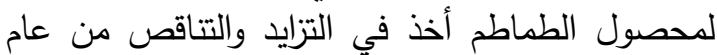

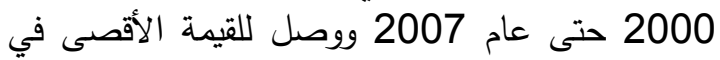
عام 2017 حيث بلغ حوالي 1513 دولار للطن وأخذ

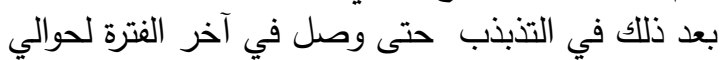
1169 دولار للطن لعام 2018، ويتضح من معالة التالة

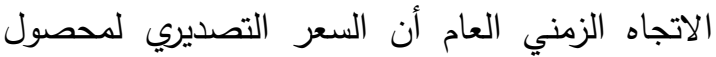

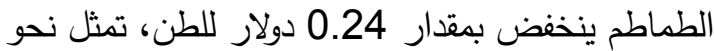

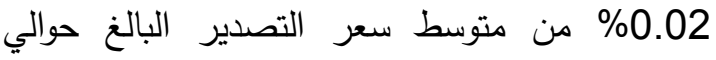
1136 دولار/طن وقد بلغ معامل التحديد نحو 0.02 أي أن حوالي 64\% من التغيرات الحادثة في السعر

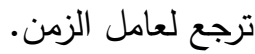

ثانيا: أهم الدول المصدرة للطماطم على مستوى العالم خلال الفترة (2000 - 2018) تبين البيانات الواردة بالجدول رقم (3) أن متوسط

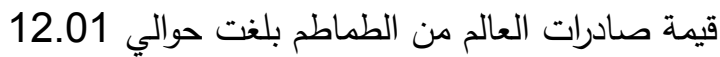
مليون دولار وقد ارتعت قيمة صنادرات العالم من

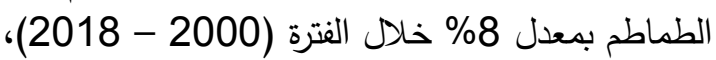
وبلغ متوسط إجمالي قيمة الصادرات لأكبر 10 دول نحو

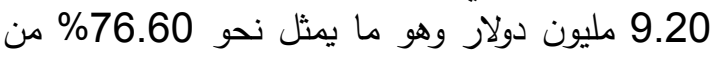
متوسط إجمالي قيمة صادرات العالم خلال فترة الدراسة، احتلت المكسيك المركز الأول من بين الدول المصدئ الديدرة

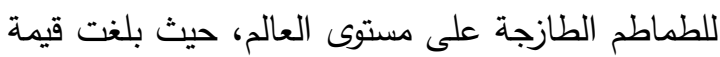

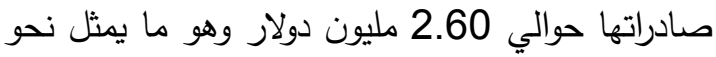

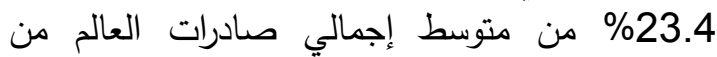
الطماطم الطازجة خلال الفترة (2000 - 2018)،

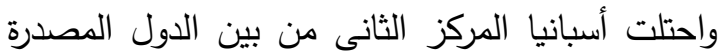

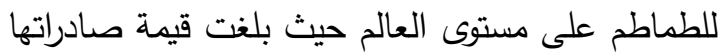

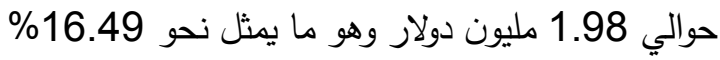
من متوسط إجمالي قيمة الصادرات للطماطم الطازجة على مستوى العالم، وتحتل هولندا المركز الثالث بقيمة الثادية

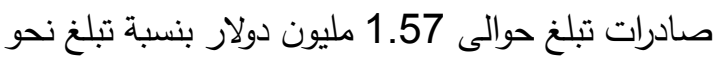

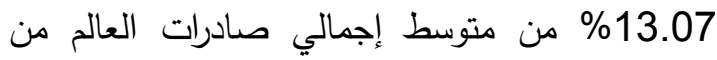

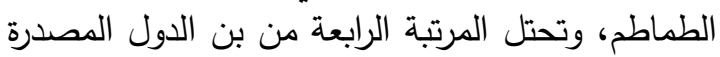
لمحصول الطماطم المغرب بقيمة تصديرية تبلغ حوالى بلى الكي

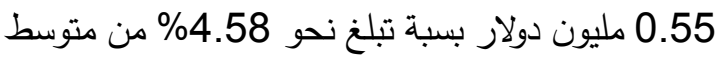

جدول 1. كمية وقيمة وسعر صادرات محصول الطماطم خلال الفترة (2000 - 2018)

\begin{tabular}{|c|c|c|c|}
\hline (دولار/طن) & القيمة & (الكمية & السنة \\
\hline 260 & 454 & 1745 & 2000 \\
\hline 248 & 1117 & 4510 & 2001 \\
\hline 250 & 941 & 3760 & 2002 \\
\hline 254 & 819 & 3224 & 2003 \\
\hline 229 & 1643 & 7188 & 2004 \\
\hline 203 & 3753 & 18470 & 2005 \\
\hline 229 & 1541 & 6732 & 2006 \\
\hline 205 & 4077 & 19891 & 2007 \\
\hline 1439 & 4565 & 3172 & 2008 \\
\hline 833 & 19887 & 23867 & 2009 \\
\hline 1178 & 6712 & 5700 & 2010 \\
\hline 307 & 19097 & 62248 & 2011 \\
\hline 1220 & 28735 & 23549 & 2012 \\
\hline 809 & 60532 & 748013 & 2013 \\
\hline 1148 & 70936 & 61800 & 2014 \\
\hline 1241 & 72869 & 58714 & 2015 \\
\hline 1054 & 65999 & 62617 & 2016 \\
\hline 1513 & 31726 & 20964 & 2017 \\
\hline 1169 & 48863 & 41791 & 2018 \\
\hline 1136 & 23382 & 26565 & المتوسط \\
\hline 0.91 & 48409 & 40046 & التفير \\
\hline 125 & 48.30 & 66.34 & معدل \\
\hline
\end{tabular}

المصدر: الجهاز المركزي للتعبئة العامة والإحصاء، قاعدة بيانات التجارة الخارجية.

فقد بلغ الحد الأدنى عام 2000 بقيمة تصديرية بلغت حوالي 454 ألف دولار في حين بلغ الحد الأقصى بلى حوالي 72869 ألف دولار وذلف ولك في في عام 2015 وتتاقصت في آخر الفترة حيث وصلت لحوالي 48863 ألف دولار عام 2018، وتوضح الزئ معادلة الاتجاه الزمني العام الزيادة السنوية المعنوية إحصائياً للقيمة التصديرية التحاهية الزينية

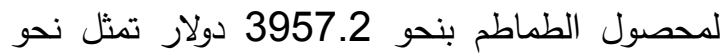

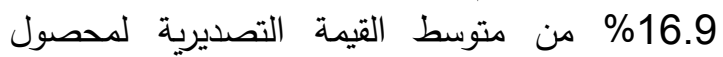
الطماطم خلال فترة الدراسة والبالغ حوالي 23383 ألف الف

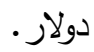


وصدرت المكسيك الطن من الطماطم الطازجة بما قيمته

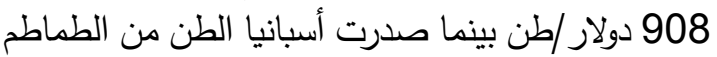

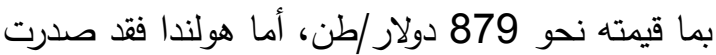
طن الطماطم بحوالي 650 دولار /طن.
إجمالي صادرات العالم من الطماطم ويلاحظ من الجدول

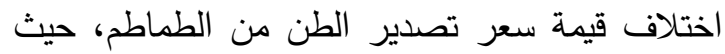
صدرت سوريا الطن بما قيمته تصدير الطن 3050 دولار /طن بينما لطناف كانت الأردن تصدره بما قيمته 1877 دولار/طنا

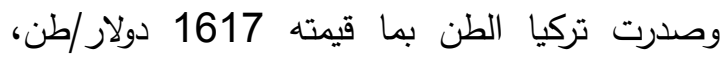

جدول 2. معادلات الاتجاه الزمني العام لكمية وقيمة وسعر تصدير محصول الطماطم خلال الفترة (2018-2000)

\begin{tabular}{|c|c|c|c|}
\hline $\mathbf{F}$ & $\mathbf{R}^{2}$ & المعادلة & المؤشر \\
\hline 19.63 & 0.53 & 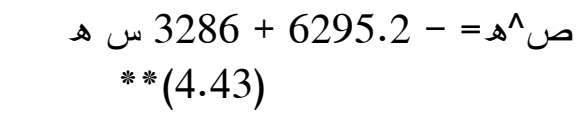 & كمية \\
\hline 36.7 & 0.68 & ص^ هـ - -3957.2 س هـ & قيمة \\
\hline 30.3 & 0.64 & 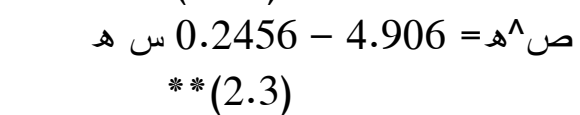 & سعر \\
\hline
\end{tabular}

المصدر: حسبت من جدول رقم (1)

جدول 3. متوسط كمية وقيمة صادرات أهم الدول المصدرة للطماطم على مستوى العالم خلال الفترة (2000 -

\begin{tabular}{|c|c|c|c|c|c|}
\hline متوسط قيمة الطن & $\%$ & كمية الصادرات & $\%$ & قيمة الصادرات & البيان \\
\hline 908 & 18.91 & 2364 & 21.65 & 2.60 & المكسيك \\
\hline 879 & 13.94 & 1741 & 16.49 & 1.98 & أسبانيا \\
\hline 650 & 8.17 & 1021 & 13.07 & 1.57 & هولندا \\
\hline 1064 & 5.14 & 642.1 & 4.58 & 0.55 & المغرب \\
\hline 733 & 3.17 & 395.6 & 4.50 & 0.54 & أمريكا \\
\hline 668 & 2.68 & 333.6 & 4.16 & 0.50 & فرنسا \\
\hline 794 & 3.17 & 389.2 & 4.08 & 0.49 & بلجيكا \\
\hline 1617 & 6.22 & 776 & 4.00 & 0.48 & ت تركيا \\
\hline 1877 & 5.26 & 656.7 & 2.91 & 0.35 & الأردن \\
\hline 3050 & 3.42 & 427.3 & 1.17 & 0.14 & سوريا \\
\hline- & 70.08 & 8746.5 & 76.6 & 9.2 & متوسط إجمالي الدول \\
\hline- & 29.2 & 3644.4 & 23.4 & 2.18 & باقي دول العالم \\
\hline - & 100 & 12390.9 & 100 & 12.01 & متوسط كمية وقيمة \\
\hline
\end{tabular}

المصدر: جمعت وحسبت من موقع منظمة الأغذية والزراعة Faostat .FAO الجهاز المركزى للتعبئة العامة والإحصاء، نشرة التجارة الخارجية، أعداد مختلفة. خريطة التجارة التابعة للأمم المتحدة www. trade_map.org 
رابعا: التوزيع الجغرافي للصادرات المصرية من الطماطم خلال الفترة (2008 - 2018)

التوزيع الجغرافي لصادرات مصر من الطماطم: بلغ عدد الأسواق التي تصدر إليها مصر الئر الطماطم الطازج أكثر

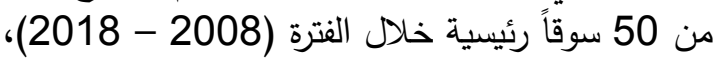

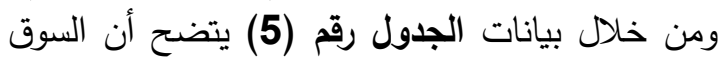

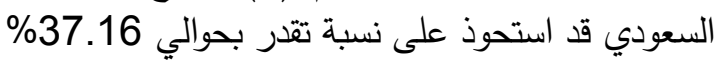
من صادرات مصر من الطماطم الطازجة أو المبردة،

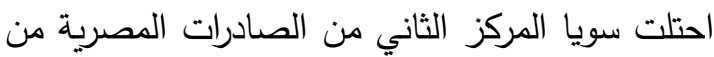

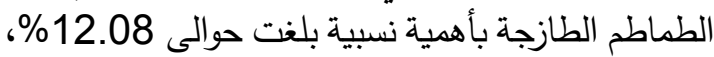

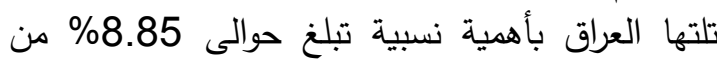
إجمالي الصادرات المصرية من الطماطم الطازجة خلال

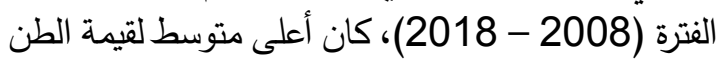

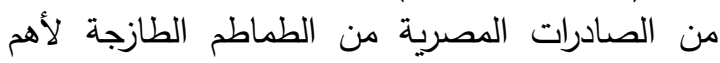

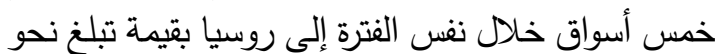

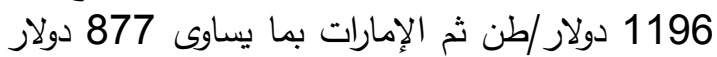

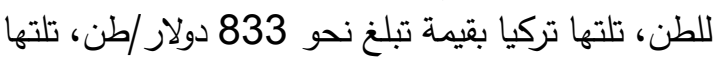
العراق بقيمة تبلغ نحو 813 دولار /طن، تلتها إيطاليا بما تباليا

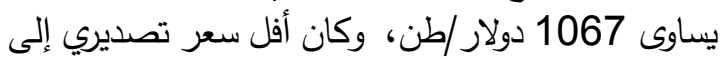
أمريكا بما يساوى 601 دولار للطن.

خامسا: أهم مؤشرات قياس القدرة التنافسية لصادرات مصر من الطماط المؤيرات

يتتاول هذا الجزء أهم المؤشرات الاقتصادية للقدرة

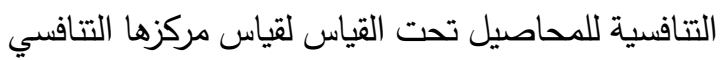
في الأسواق العالمية ومن أهم وأشهر مؤشرات التنافسية التي يمكن استخدامها مؤشر الميزة النسبية الظاهرية،

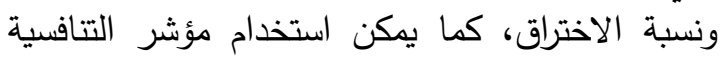

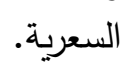

ثالثا : أهم الدول المستوردة للطماطم على مستوى العالم خلال الفترة (2000 - 2018)

يتضح من بيانات الجدول رقم (4) أن متوسط

واردات العالم من الطماطم بلغت حوالي 12729043

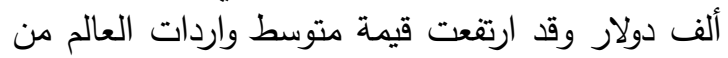
الطماطم بمعدل 10\% خلال الفترة (2000 - 2018)، وتيطة وبلغ متوسط إجمالي قيمة الواردات لأكبر 13 دول نحو الحوة 5313707 ألف دولار وهو ما يمثل نحو

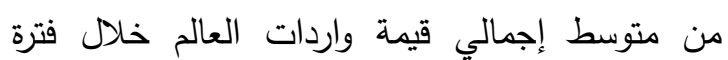

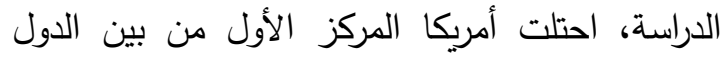

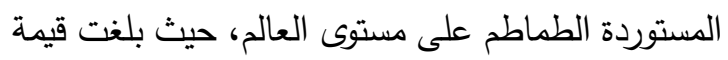

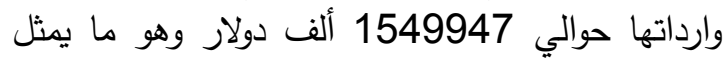

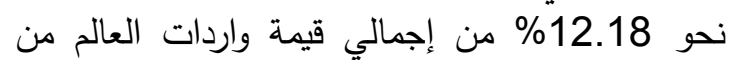

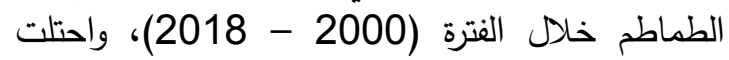
ألمانيا المركز الثاني من بين الدول المستوردة الطماطم على مستوى العالم حيث بلغت لئ قيمة وارداتها حوالي الماني

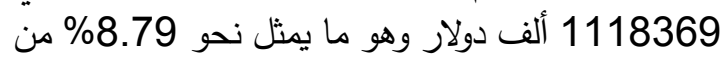

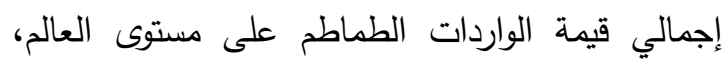
وتأتى المملكة المتحدة في المركز الثالث بقيمة إستيرادية الثية

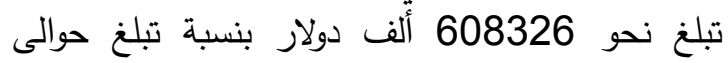
4.49 من متوسط إجمالى واردات العالم من الطماطح

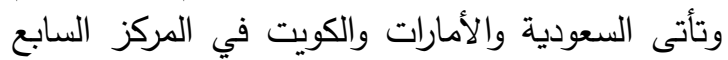
والتاسع والثالث عشر حيث تبلغ القيمة الإستيرادية لكل

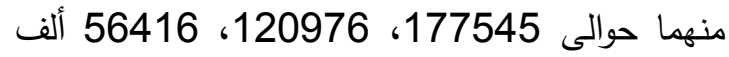

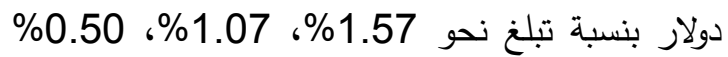

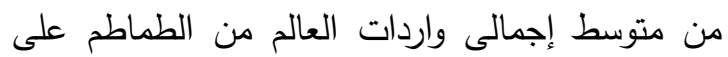
التوالى ويلاحظ من الجدول اختلاف قيمة سعر الاستيراد

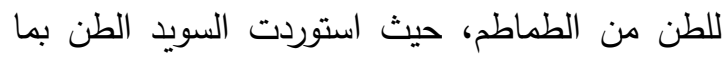

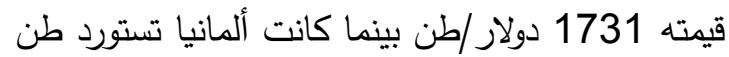
الطماطم بحوالى 1649 دولار/طن وتستورد أمريكا طن بن الطن 1243

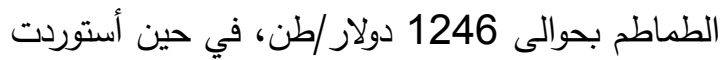
السعودية والأمارات والكويت طن الطماطم بحوالى 347 دولى 34 دولار/طن، 615 دولار/طن، 426 دولار /طن. 
جدول 4. أهم الدول المستوردة للطماطح على مستوى العالم خلال الفترة (2000 - 2018)

\begin{tabular}{|c|c|c|c|c|c|}
\hline متوسط قيمة & $\%$ & ألثية المستوردة & $\%$ & قَيمة الواردات & البيـــــان \\
\hline 1.246 & 10.98 & 1244.352 & 12.18 & 1549947 & أمريكا \\
\hline 1.649 & 5.98 & 678.282 & 8.79 & 1118369 & ألمانيا \\
\hline 1.047 & 4.27 & 484.155 & 3.98 & 506932 & فرنسا \\
\hline 0.990 & 4.49 & 509.377 & 3.96 & 504041 & 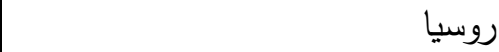 \\
\hline 1.591 & 3.37 & 382.237 & 4.78 & 608326 & المملكة المتحدة \\
\hline 1.331 & 1.67 & 189.644 & 1.98 & 252332 & كندا \\
\hline 0.347 & 1.57 & 177.545 & 0.48 & 61634 & السعودية \\
\hline 1.322 & 1.77 & 200.816 & 2.09 & 265478 & هولندا \\
\hline 0.615 & 1.07 & 120.976 & 0.58 & 74439 & الأمارات \\
\hline 1.172 & 0.88 & 99.761 & 0.92 & 116924 & إيطاليا \\
\hline 1.089 & 0.74 & 83.549 & 0.71 & 90996 & التشيك \\
\hline 1.731 & 0.72 & 81.042 & 1.10 & 140256 & السويد \\
\hline 0.426 & 0.50 & 56.416 & 0.19 & 24033 & الكويت \\
\hline- & 38.01 & 4.308 .152 & 41.74 & 5313707 & متوسط إجمالي الدول \\
\hline- & 61.99 & 7.026 .056 & 58.26 & 7415336 & متوسط باقى دول العالم \\
\hline- & 100 & 11334.208 & 100 & 12729.043 & العالم \\
\hline
\end{tabular}

المصدر: جمعت وحسبت من موقع منظمة الأغذية والزراعة FAOSTAT . FAO الجهاز المركزى للتعبئة العامة والإحصاء، نثرة التجارة الخارجية، أعداد مختلفة. جدول 5. أهم أسواق الصادرات المصربة الطماطم خلال الفترة (2008 - 2018)

\begin{tabular}{|c|c|c|c|c|}
\hline ترتيب الدول في & الطن الف دولار & للصادرات المصبية النسبية & قيمة الصادرات المصرية & البيـــــــان \\
\hline 1 & 0.622 & 37.16 & 170923 & السعودية \\
\hline 2 & 0.523 & 12.08 & 55550 & سوريا \\
\hline 3 & 0.813 & 8.85 & 40705 & العراق \\
\hline 4 & 0.877 & 8.00 & 36786 & الأمارات \\
\hline 5 & 0.833 & 6.45 & 29666 & تركيا \\
\hline 6 & 0.762 & 5.96 & 27418 & هولندا \\
\hline 7 & 0.178 & 5.80 & 26696 & ليبيا \\
\hline 8 & 0.431 & 5.63 & 25890 & الكويت \\
\hline 9 & 1.196 & 2.94 & 13539 & روسيا \\
\hline 10 & 0.903 & 1.19 & 5452 & قطر \\
\hline 11 & 0.577 & 1.10 & 5052 & بلجيكا \\
\hline 12 & 0.796 & 1.06 & 4866 & بربطانيا \\
\hline- & - & 96.22 & 442543 & إجمالى الدول \\
\hline
\end{tabular}

المصدر : جمعت وحسبت من موقع منظمة الأغذية والزراعة FAOSTAT .FAO

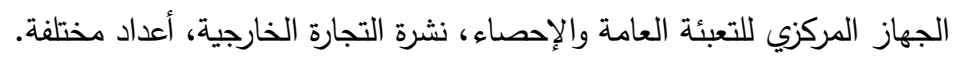

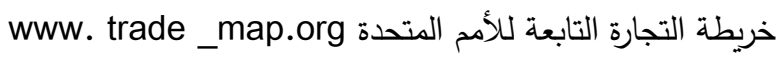


الاختراق للطماطم المصرية للسوق الهولندي يبلغ حوالي 0.038 وهذا يعنى أن صادرات الطماطم المصرية إلى لـئي

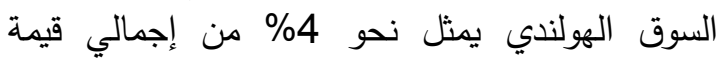

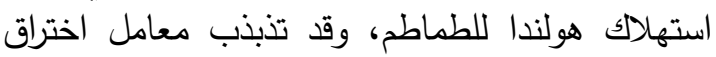

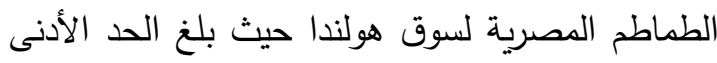

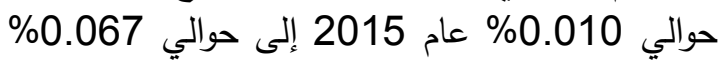
عام 2017 وهذا يعنى أن السوق الهولندي لدية من الهن

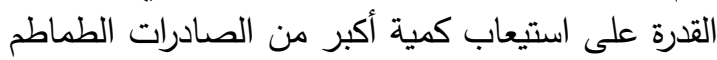

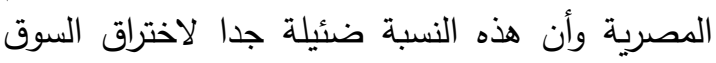

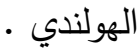

كما نجد أن معامل اختراق الطماطم المصرية لسوق

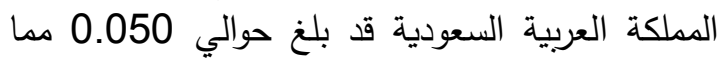
يعنى أن صادرات الطماطم المصرية إلى المملكة العربية

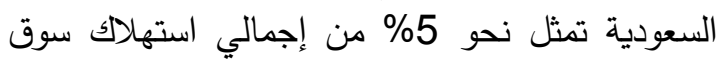

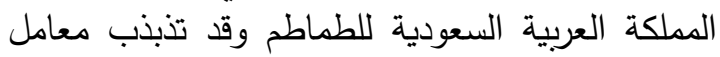

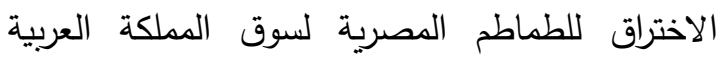

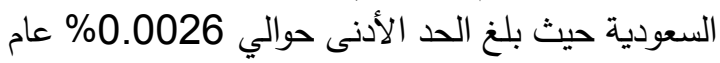
2010 وبلغ الحد الأقصى حوالي 13 0.13\% عام الألي 2015

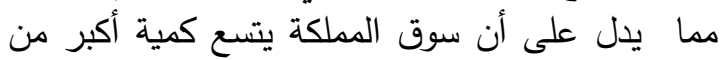

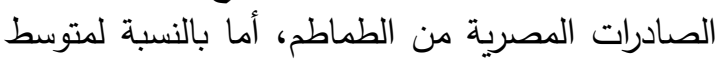
معامل الاختراق للسوق الإماراتي فقد بلغ حوالي 0.018

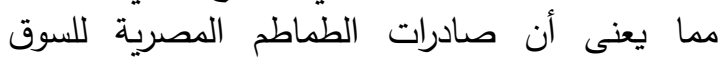

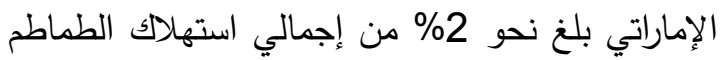

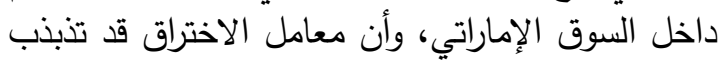

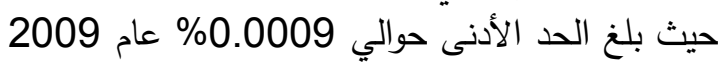
إلى حوالي 0.054\% عام 2016 مما يعنى أن هناك

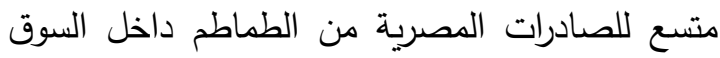

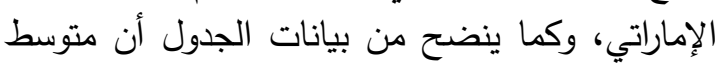

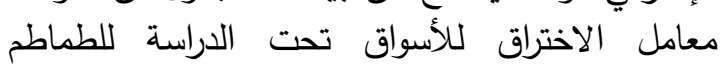

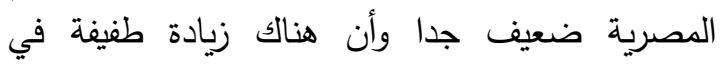

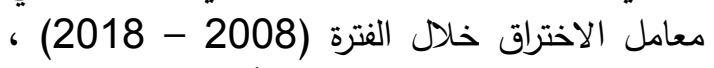
ومن هنا يجب العمل على دراسة أسباب هذا التذبذب لتبن

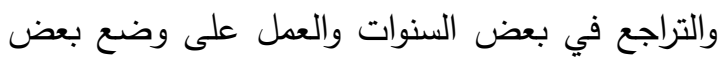
السياسات التصديرية التي تعمل على علاج هذا التذبذب وضن والتراجع. - (النيان.
أ- مؤشر الميزة النسبية الظاهرية لمحصول الطماطم

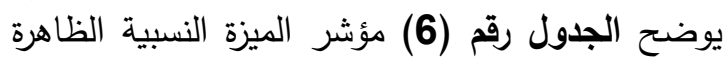

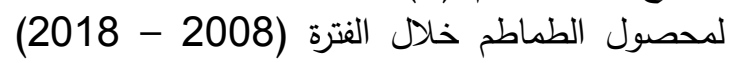
حيث يتضح أنه على الرغم من أن قيمة المؤشر تزيد

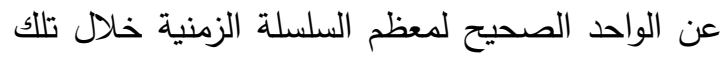

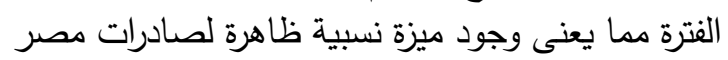

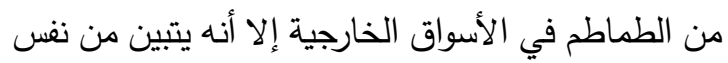

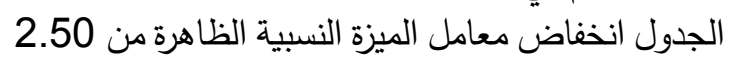

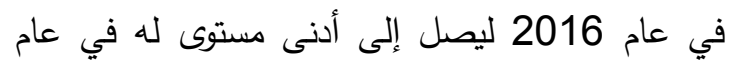
2018 إلى حوالي 0.19 مما يعنى وجود تدهور في الفي لئي السوق التتافسي لهذا المحصول في الأسواق العالمية،

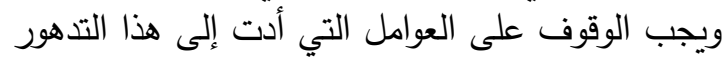

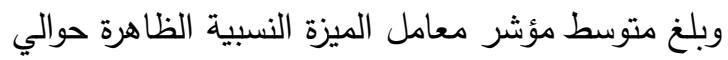

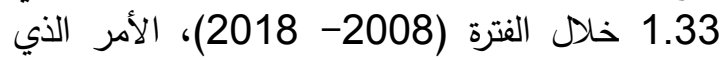
يعنى أن هذا المحصول التصديرى من المحاصيل الهامة

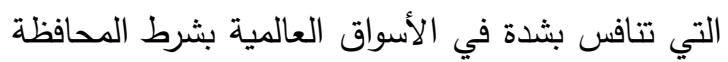

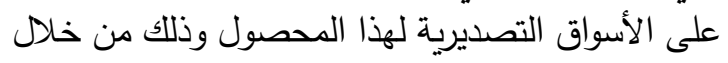
مطابقة المواصفات المطلوبة للسوق العالمي وفتح أسواق

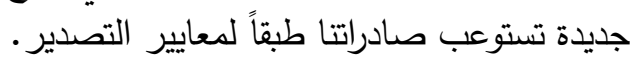

ب- معامل اختراق الأسواق لمحصول الطماطم

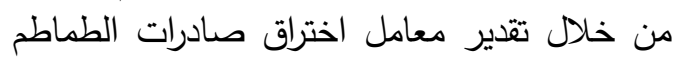

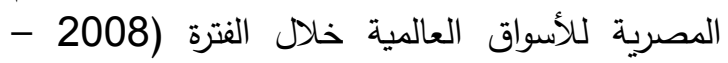

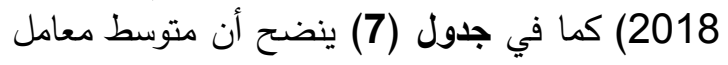

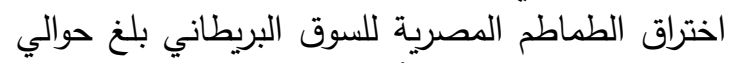

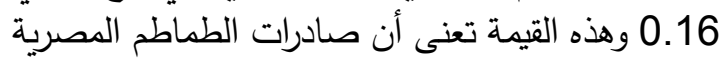

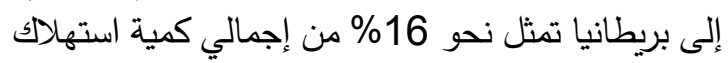
الطماطم داخل بريطانيا خلال الفترة (2008 - 2018) كما نجد أن معامل اختراق الطماطم المصرية لبريطانيا في تذبذب حيث بلغ الحد الأدنى لمعامل الاختراق حوالي لطي لئي

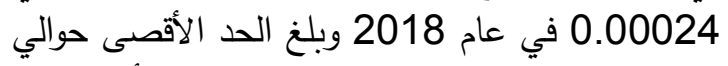

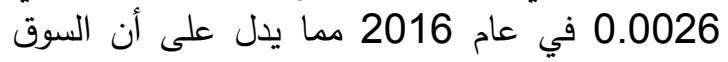

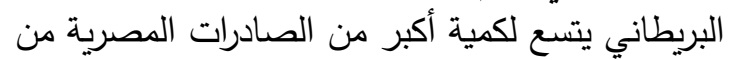

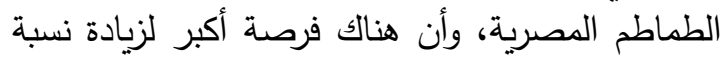

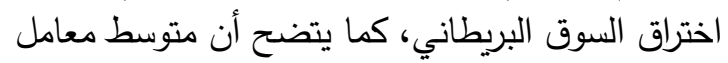


جدول 6. تقدير معامل الميزة النسبية الظاهرة لصادرات الطماطم خلال الفترة (2008 - 2018)

\begin{tabular}{|c|c|c|c|c|c|}
\hline الميزة النسبية & قيمة الصادرات & قيمة صادرات & قيمة الصادرات & قيمة صادرات & البيان \\
\hline الظاهرة & الزراعية العالمية & الطعالمية & المصرية الزراعية & الطماطم & السنة \\
\hline 0.58 & 1067553.10 & 7371.48 & 2177 & 8.65 & 2008 \\
\hline 0.61 & 950959.94 & 7009.06 & 4407 & 19.9 & 2009 \\
\hline 1.15 & 1084742.34 & 8251.07 & 2918 & 25.55 & 2010 \\
\hline 0.58 & 1320239.08 & 8501.64 & 5094 & 19.1 & 2011 \\
\hline 1.13 & 1337670.64 & 8181.58 & 4141 & 28.59 & 2012 \\
\hline 1.97 & 1396562.91 & 8803.01 & 4867 & 60.33 & 2013 \\
\hline 2.53 & 1414953.33 & 9238.37 & 4354 & 71.78 & 2014 \\
\hline 2.40 & 1264550.29 & 8348.99 & 4267 & 67.62 & 2015 \\
\hline 2.50 & 1277460.53 & 8603.40 & 3953 & 66.45 & 2016 \\
\hline 1.00 & 1401421.29 & 9025.98 & 4993 & 32.15 & 2017 \\
\hline 0.19 & 1339440.91 & 8814.69 & 4473 & 5.56 & 2018 \\
\hline 1.33 & 1259595.85 & 8377.21 & 4149 & 36.88 & المتوسط \\
\hline
\end{tabular}

FAOSTAT .FAO المصدر: موقع منظمة الأغذية والزراعة

الجهاز المركزي للتعبئة العامة والإحصاء، نشرة التجارة الخارجية، أعداد مختلفة. خريطة التجارة التابعة للأمم المتحدة Www. trade _map.org

جدول 7. معامل اختراق محصول الطماطم للأسواق العالمية خلال الفترة (2008 - 2018)

\begin{tabular}{|c|c|c|c|c|c|}
\hline الاخترلق معلمل & صن الطماطي & الطماطر من العالم & إنتاج بريطانيا & من الطماطم لبريطانيا & السنة \\
\hline 0.00261 & 5011 & 419045 & 88690 & 1311 & 2008 \\
\hline 0.00179 & 6714 & 396675 & 86800 & 854 & 2009 \\
\hline 0.00258 & 4613 & 386509 & 89320 & 1217 & 2010 \\
\hline 0.00151 & 5591 & 414381 & 89800 & 752 & 2011 \\
\hline 0.00027 & 6185 & 409238 & 83000 & 129 & 2012 \\
\hline 0.00045 & 3713 & 422971 & 91100 & 228 & 2013 \\
\hline 0.00071 & 3022 & 395513 & 98500 & 351 & 2014 \\
\hline 0.00054 & 3748 & 375619 & 97200 & 255 & 2015 \\
\hline 0.00140 & 3636 & 380444 & 96556 & 662 & 2016 \\
\hline 0.00052 & 4245 & 374633 & 90627 & 242 & 2017 \\
\hline 0.00024 & 3941 & 377539 & 93591.5 & 113 & 2018 \\
\hline 0.00115 & 4583.5 & 395687.9 & 91380.4 & 555.8 & لمتوسط \\
\hline
\end{tabular}

www.fao.org.eg المصدر: جمعت وحسبت من منظمة الأغذية والزراعة 
تابع جدول 7. معامل اختراق محصول الطماطم للأسواق العالمية خلال الفترة (2008 - 2018)

\begin{tabular}{|c|c|c|c|c|c|}
\hline معامل الاخترلق & صن الطماطر هولندا & الطماطم من العالم هولندا من & من الطماط هولندا & من الطماطر هولندات & السنة \\
\hline 0.03020 & 839550 & 202391 & 730000 & 2804 & 2008 \\
\hline 0.03907 & 923954 & 193445 & 800000 & 2715 & 2009 \\
\hline 0.14712 & 943119 & 191544 & 815000 & 9331 & 2010 \\
\hline 0.01340 & 1023496 & 209434 & 815000 & 12356 & 2011 \\
\hline 0.03137 & 977664 & 206996 & 805000 & 1077 & 2012 \\
\hline 0.01901 & 1013529 & 196880 & 855000 & 729 & 2013 \\
\hline 0.02639 & 1021484 & 180075 & 900000 & 1546 & 2014 \\
\hline 0.01011 & 1010843 & 168435 & 890000 & 481 & 2015 \\
\hline 0.01073 & 992601 & 172544 & 900000 & 858 & 2016 \\
\hline 0.06709 & 1089230 & 220952 & 910000 & 2799 & 2017 \\
\hline 0.02106 & 1040916 & 196748 & 905000 & 1281 & 2018 \\
\hline 0.038 & 988762.32 & 194494.91 & 847727.27 & 3270.64 & المتوسط \\
\hline
\end{tabular}

www.fao.org.eg المصدر: جمعت وحسبت من منظمة الأغذية والزراعة

تابع جدول 7. معامل اختراق محصول الطماطم للأسواق العالمية خلال الفترة (2008 - 2018)

\begin{tabular}{|c|c|c|c|c|c|}
\hline معامل الاخترلق & صن & واردات السعودية من & من الطماطم إنتاج السعودية & صادرات مصر من & السنة \\
\hline 0.00309 & 5269 & 103498 & 522152 & 1919 & 2008 \\
\hline 0.00520 & 2070 & 113272 & 542589 & 3401 & 2009 \\
\hline 0.00261 & 2070 & 124789 & 492402 & 1605 & 2010 \\
\hline 0.00538 & 1981 & 135291 & 520034 & 3518 & 2011 \\
\hline 0.00215 & 3340 & 159347 & 549119 & 1516 & 2012 \\
\hline 0.05052 & 4996 & 165589 & 544464 & 35616 & 2013 \\
\hline 0.04459 & 5062 & 168818 & 280293 & 19799 & 2014 \\
\hline 0.13473 & 5105 & 185648 & 288618 & 63210 & 2015 \\
\hline 0.14017 & 5377 & 179500 & 305203 & 67187 & 2016 \\
\hline 0.07276 & 906 & 152752 & 306389 & 33343 & 2017 \\
\hline 0.09316 & 3141.5 & 166126 & 305796 & 43673 & 2018 \\
\hline 0.050 & 3574 & 150421 & 423369 & 24981 & المتوسط \\
\hline
\end{tabular}

www.fao.org.eg المصدر: جمعت وحسبت من منظمة الأغذية والزراعة 
تابع جدول 7. معامل اختراق محصول الطماطم للأسواق العالمية خلال الفترة (2008 - 2018)

\begin{tabular}{|c|c|c|c|c|c|}
\hline معامل الاختراق & من الطماطر الأمارات & الطماط من العالم من & إنتاج الأمارات & صادرات مصر من الطماط & السنة \\
\hline 0.00202 & 5269 & 103498 & 127405 & 456 & 2008 \\
\hline 0.00090 & 2070 & 113272 & 68298 & 162 & 2009 \\
\hline 0.00829 & 2070 & 124789 & 47411 & 1410 & 2010 \\
\hline 0.00738 & 1981 & 135291 & 58668 & 1417 & 2011 \\
\hline 0.00946 & 3340 & 159347 & 35470 & 1812 & 2012 \\
\hline 0.00893 & 4996 & 165589 & 33130 & 1730 & 2013 \\
\hline 0.01550 & 5062 & 168818 & 41886 & 3187 & 2014 \\
\hline 0.03311 & 5105 & 185648 & 46550 & 7520 & 2015 \\
\hline 0.05372 & 5377 & 179500 & 43791 & 11706 & 2016 \\
\hline 0.02271 & 906 & 152752 & 41752 & 4397 & 2017 \\
\hline 0.03929 & 1234 & 166126 & 42772 & 8159 & 2018 \\
\hline 0.018 & 3401 & 150421 & 53376 & 3814 & المتوسط \\
\hline
\end{tabular}

www.fao.org.eg المصدر: جمعت وحسبت من منظمة الأغذية والزراعة

المصرية ليس لله ميزة تتافسية سعرية في السوق

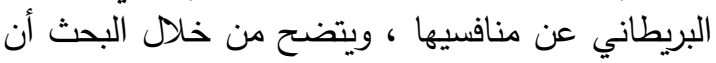

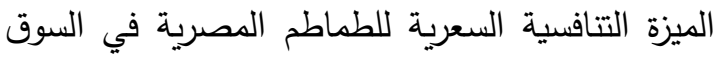

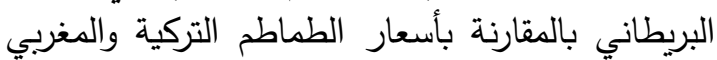

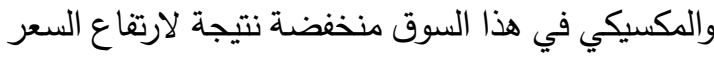

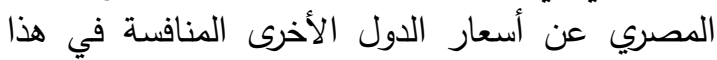

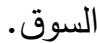
3-السوق الهولندي: يعتبر كلاً من السوق التركي والسوق المغربي والسوق الأسباني من أهم الأسواق الستري المنافسة للسوق المصري لتصدير الطماطم إلى السوق النقان

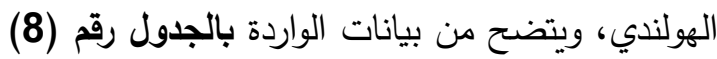

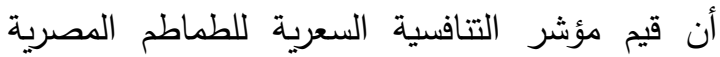

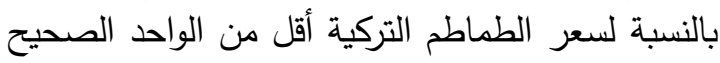
في معظم سنوات الدراسة ماعدا عامي 2011 2013، 2010، 2011 وقد بلغ متوسط مؤشر التتافسية السعرية حوالي

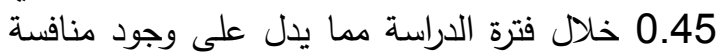

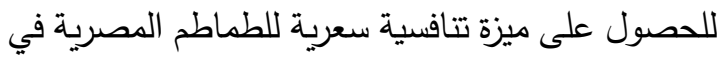

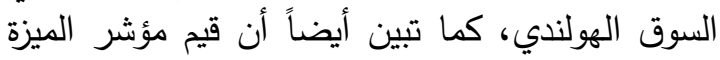

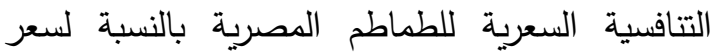

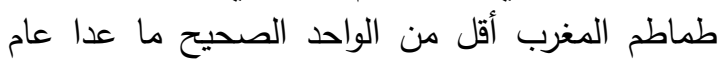
2013 مما يعنى أنه كان هناك الوالك منافسة للطماطم عالم
ج-مؤشر التنافسية السعرية لمحصول الطماطر

1-السوق السعودي: تم اختيار كل من المكسيك

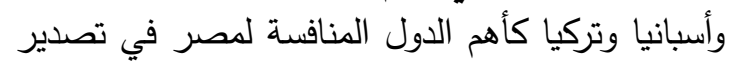

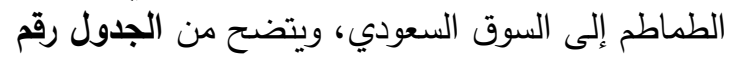

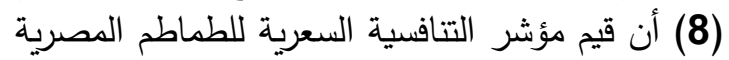
بالنسبة لأسعار الطماطم المكسيكية والاسبانية والتركية

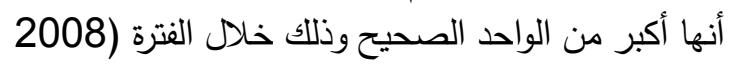
- 2018) أي أن الطماطم المصرية لها ميزة سعرية الهرية

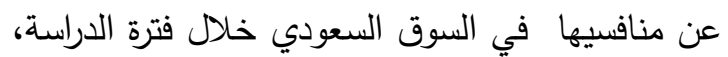

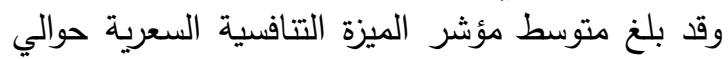
2.58 خلال فترة الدراسة . 2-السوق البريطاني: أما بالنسبة لمؤشر الميزة

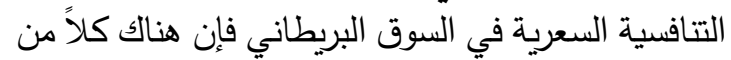

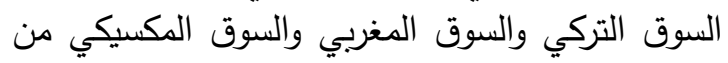

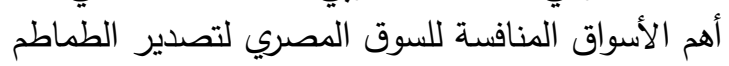

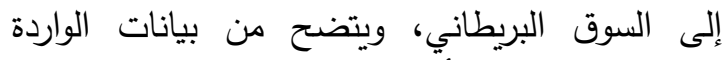
بالجدول رقم (8) أن قيم مؤشر التنافسية السعرية للطماطم المصرية بالنسبة لسعر الطماطم التركية التركية والمغربية والمكسيكية أقل من الواحد الصحيح خلانل فترة

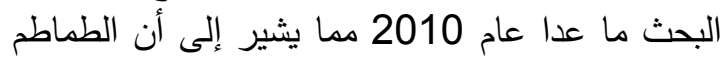


متوسط مؤشر التتافسية السعرية حوالي 0.73 خلال فترة

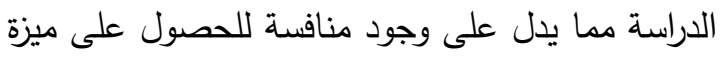

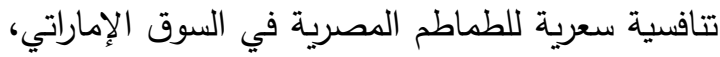

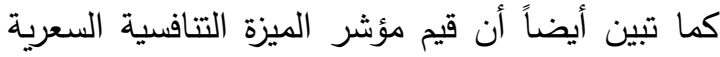

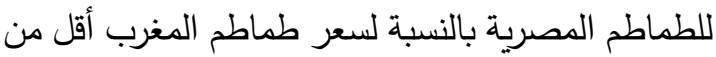

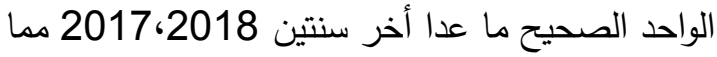
يعنى أن هناك إعادة للدكانة التتافسية السعرية للطماطم

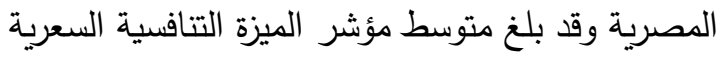

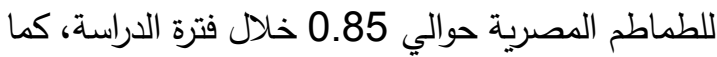

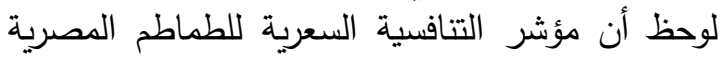

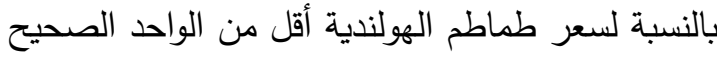

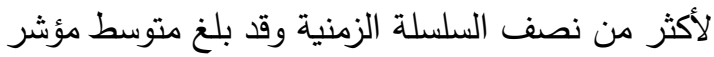

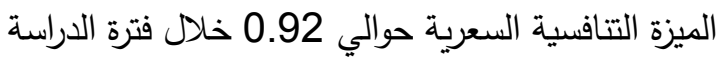

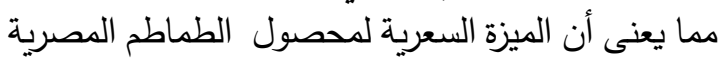

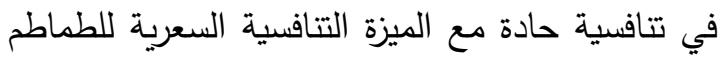

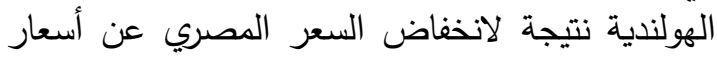

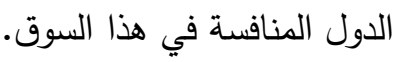

المصرية في هذه السنة وقد بلغ متوسط مؤشر الميزة التتافسية السعرية للطماطم المصرية حوالي 0.21 خلال

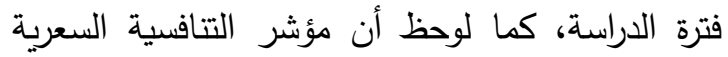

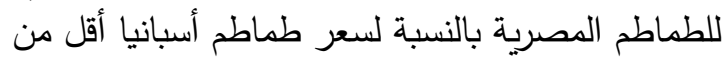

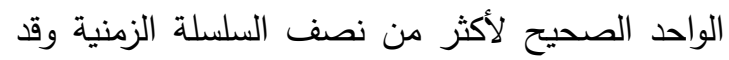
بلغ متوسط مؤشر الميزة التتافسية السعرية حوالي 0.56

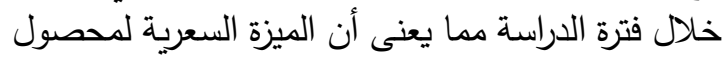

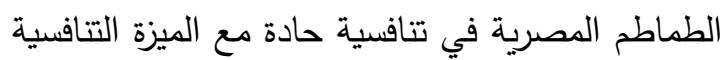

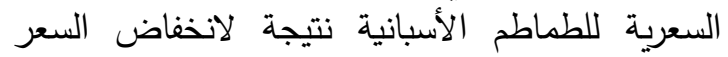

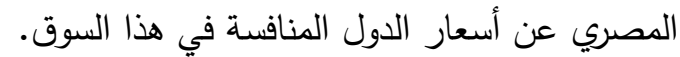

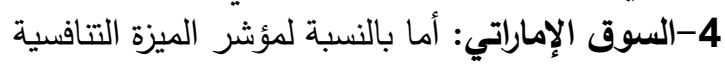

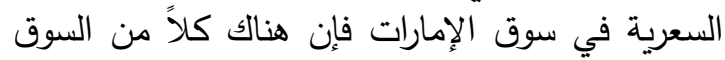
التركي والسوق المغربي والسوق والهولندي من أهم الهمان

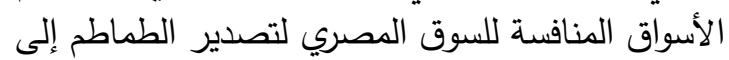

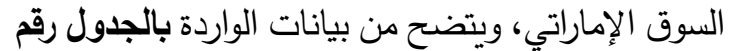

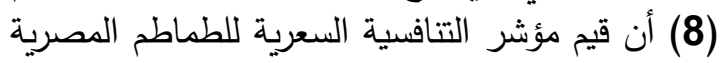

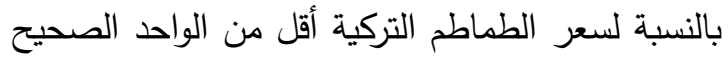

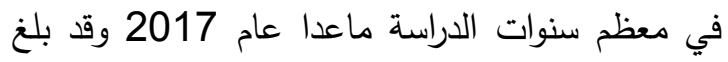

جدول 8. مؤشر التتافسية السعرية للطماطم المصرية مع سعر الطماطم لأهم الدول المنافسة في أهم الأسواق العالمية

\begin{tabular}{|c|c|c|c|c|c|c|c|c|}
\hline السعربة & سركيا & السعبية & سعبرانيا & السعربية & سعريك & مصر & السنة & الاولة \\
\hline 2.79 & 430 & 5.59 & 863 & 3.27 & 504 & 154.4 & 2008 & \multirow{11}{*}{ العملكة العربية } \\
\hline 3.66 & 409 & 7.25 & 809 & 3.97 & 443 & 111.6 & 2009 & \\
\hline 4.05 & 663 & 5.69 & 930 & 3.16 & 517 & 163.6 & 2010 & \\
\hline 1.76 & 458 & 2.35 & 613 & 1.71 & 444 & 260.6 & 2011 & \\
\hline 2.27 & 560 & 3.45 & 771 & 2.10 & 481 & 212.1 & 2012 & \\
\hline 2.32 & 474 & 3.34 & 720 & 1.99 & 437 & 208.6 & 2013 & \\
\hline 1.98 & 480 & 1.80 & 689 & 2.10 & 412 & 206.6 & 2014 & \\
\hline 3.65 & 396 & 2.23 & 361 & 2.74 & 420 & 200.2 & 2015 & \\
\hline 3.01 & 509 & 4.42 & 311 & 3.91 & 382 & 139.6 & 2016 & \\
\hline 2.62 & 299 & 3.12 & 438 & 3.59 & 388 & 99.2 & 2017 & \\
\hline 2.58 & 312 & 3.24 & 372 & 2.37 & 428 & 119.4 & 2018 & \\
\hline 2.58 & 480 & 3.24 & 604.2 & 2.37 & 441.5 & 186.3 & \multicolumn{2}{|c|}{ المتوسط } \\
\hline
\end{tabular}

www.fao.org.eg المصدر : جمعت وحسبت من منظمة الأغذية والزراعة 
تابع جدول 8. مؤشر التنافسية السعرية للطماطم المصرية مع سعر الطماطم لأهم الدول المنافسة في أهم الأسواق العالمية خلال الفترة (2008 - 2018)

\begin{tabular}{|c|c|c|c|c|c|c|c|c|}
\hline السعرية & سكسيك & السعربة & سعرب & السعريـة & تركيا & سعر & السنة & الدولة \\
\hline 0.89 & 504 & 0.46 & 263 & 0.76 & 430 & 568 & 2008 & \multirow{11}{*}{ البريطاني } \\
\hline 0.35 & 443 & 0.23 & 287 & 0.33 & 409 & 1254 & 2009 & \\
\hline 0.98 & 517 & 0.45 & 239 & 1.25 & 663 & 529 & 2010 & \\
\hline 0.69 & 444 & 0.40 & 261 & 0.71 & 458 & 645 & 2011 & \\
\hline 0.25 & 481 & 0.13 & 250 & 0.29 & 560 & 1922 & 2012 & \\
\hline 0.26 & 437 & 0.16 & 275 & 0.28 & 474 & 1675 & 2013 & \\
\hline 0.42 & 412 & 0.28 & 271 & 0.49 & 480 & 986 & 2014 & \\
\hline 0.17 & 420 & 0.07 & 172 & 0.16 & 396 & 2408 & 2015 & \\
\hline 0.41 & 382 & 0.21 & 199 & 0.55 & 509 & 932 & 2016 & \\
\hline 0.33 & 388 & 0.18 & 204 & 0.26 & 299 & 1165 & 2017 & \\
\hline 0.25 & 428 & 0.17 & 293 & 0.18 & 312 & 1690 & 2018 & \\
\hline 0.34 & 442 & 0.18 & 234 & 0.37 & 480 & 1300 & \multicolumn{2}{|c|}{ المتوسط } \\
\hline
\end{tabular}

www.fao.org.eg المصدر: جمعت وحسبت من منظمة الأغذية والزراعة

تابع جدول 8. مؤشر التنافسية السعرية للطماطم المصرية مع سعر الطماطم لأهم الدول المنافسة في أهم الأسواق العالمية خلال الفترة (2008 - 2018)

\begin{tabular}{|c|c|c|c|c|c|c|c|c|}
\hline السعبية & سعبرانيا & السعرية & سعر المغرب & السعرية & سركيا & مصر & السنة & الاولة \\
\hline 1.62 & 863 & 0.49 & 263 & 0.81 & 430.3 & 534 & 2008 & \multirow{11}{*}{ الهولندي } \\
\hline 0.58 & 809 & 0.21 & 287 & 0.29 & 409.0 & 1393 & 2009 & \\
\hline 1.68 & 930 & 0.43 & 239 & 1.20 & 662.7 & 554 & 2010 & \\
\hline 2.21 & 613 & 0.94 & 261 & 1.65 & 458.0 & 277 & 2011 & \\
\hline 0.42 & 771 & 0.14 & 250 & 0.30 & 560.4 & 1838 & 2012 & \\
\hline 4.47 & 720 & 1.71 & 275 & 2.95 & 474.2 & 161 & 2013 & \\
\hline 0.78 & 689 & 0.31 & 271 & 0.54 & 480.0 & 885 & 2014 & \\
\hline 0.25 & 361 & 0.12 & 172 & 0.27 & 395.7 & 1464 & 2015 & \\
\hline 0.33 & 311 & 0.21 & 199 & 0.54 & 509.4 & 936 & 2016 & \\
\hline 0.55 & 438 & 0.26 & 204 & 0.38 & 299.0 & 797 & 2017 & \\
\hline 0.11 & 372 & 0.09 & 293 & 0.09 & 312.3 & 3404 & 2018 & \\
\hline 0.56 & 628 & 0.21 & 234 & 0.45 & 505.8 & 1113 & $b$ & المت \\
\hline
\end{tabular}

www.fao.org.eg المصدر: جمعت وحسبت من منظمة الأغذية والزراعة 
تابع جدول 8. مؤشر التنافسية السعرية للطماطم الصصرية مع سعر الطماطم لأهم الدول المنافسة في أهم الأسواق

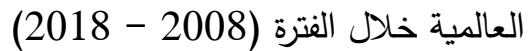

\begin{tabular}{|c|c|c|c|c|c|c|c|c|}
\hline النسبية & هولندا & السعرية & سعري & السعرية & تركيا & سعر & السنة & الدولة \\
\hline 1.62 & 982 & 0.86 & 523 & 0.83 & 506 & 607 & 2008 & \multirow{11}{*}{ الإمارتي } \\
\hline 0.56 & 736 & 0.76 & 1010 & 0.67 & 891 & 1321 & 2009 & \\
\hline 1.01 & 1002 & 0.81 & 801 & 0.77 & 763 & 991 & 2010 & \\
\hline 1.44 & 659 & 0.83 & 380 & 0.75 & 345 & 457 & 2011 & \\
\hline 0.79 & 830 & 0.95 & 1001 & 0.93 & 984 & 1053 & 2012 & \\
\hline 0.74 & 721 & 0.92 & 900 & 0.67 & 654 & 974 & 2013 & \\
\hline 0.94 & 808 & 0.81 & 700 & 0.75 & 645 & 859 & 2014 & \\
\hline 0.93 & 805 & 0.85 & 734 & 0.65 & 567 & 867 & 2015 & \\
\hline 0.81 & 670 & 0.73 & 605 & 0.55 & 456 & 831 & 2016 & \\
\hline 2.05 & 825 & 1.50 & 605 & 1.63 & 657 & 403 & 2017 & \\
\hline 1.27 & 740 & 1.04 & 605 & 0.61 & 354 & 581 & 2018 & \\
\hline 0.92 & 790 & 0.85 & 732 & 0.73 & 631 & 862 & & \\
\hline
\end{tabular}

المصدر: جمعت وحسبت من منظمة الأغذية والزراعة Www.fao.org.eg

$$
\text { المراجـع }
$$

أولاً : المراجع العربية

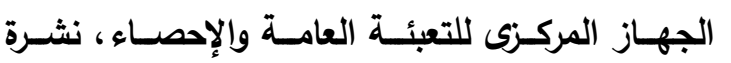
التجارة الخارجية، أعداد مختلفة.

جيهان محمــ عبد الفتـاح الجيزاوي 2011.

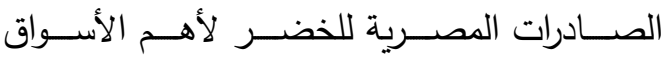

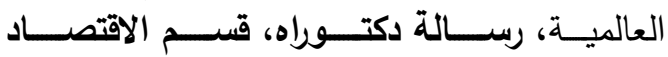

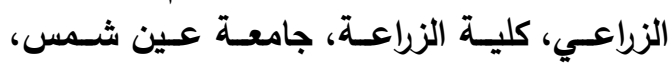

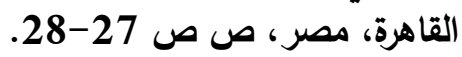

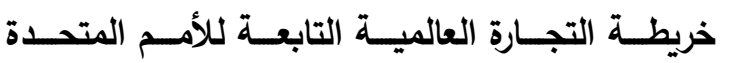
(www.TRADE_MAP.org) داليا عبد الحميد هلال يسن 2008. "دراسة القدرات

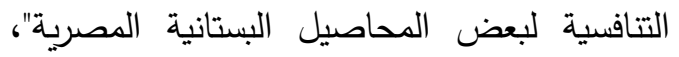
رسالة دكتوراة، قسم الاقتصاد الزراعي، كلية الئية

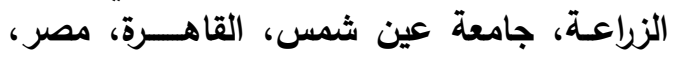
ص ص 23-27. (الزعة جاعة
1-المحافظة على الأسواق التصديرية لدحصول

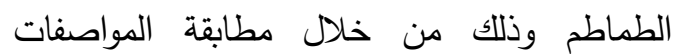

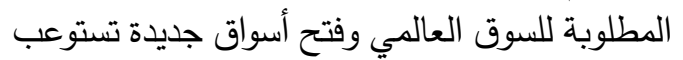
صادراتنا طبقاً لدعايير التصدير.

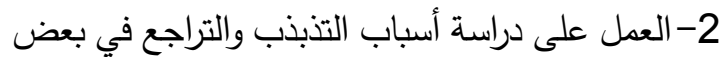

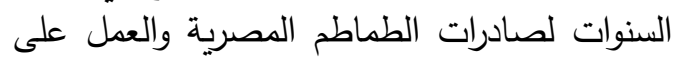
وضع بعض السياسات التصديرية التي تعمل على العى العلى علاج هذا التنبذب والتزاجع. 3-العمل على تقليل حده المنافسة السعرية لمحصول الطماطم المصرية في السوق الهولندى والبريطانى لموجهة التنافسية السعرية لكل من تركيا والمغرب النيان والمكسيك . 4-بحث امكانية الدد من تذبذب معامل الاختراق

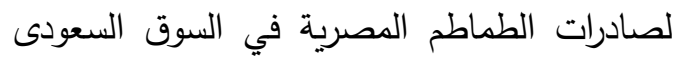

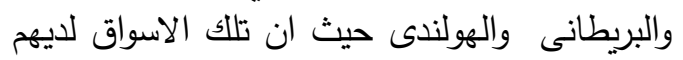
القدرة على استيعاب كميات اكبر من صادرات الاندات لانيات

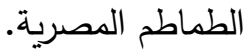


سميرة أمين عبد الحليم، محمد السيد السيد حسين، ثانياً: المراجع الأجنبية سيد محمد سيد 2010. القدرة التتافسية للصادرات الكيديات

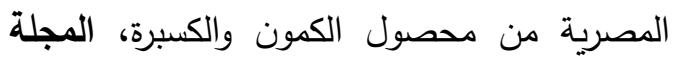

\section{U.S Agency for Internation} Development. The Internation Competitiveness of Egypt in Prespective, Previous Source.

Porter M. The Competitive Advantage of Nations, Free Press. 14 p. Sophisticated.199.
المصرية للاقتصاد الزراعي، المجلد 20، العدد (4)، الكون المبلة

$$
\text { منظمال }
$$

منظمة الأغذية والزراعة (www.FAO.org)

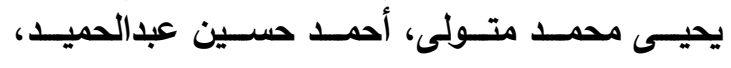

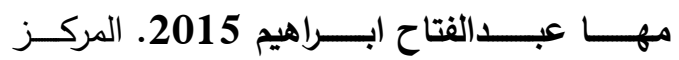

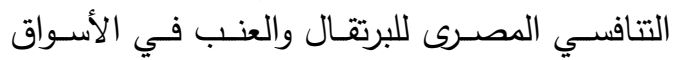

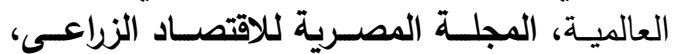

المجلد 25، العدد(1)، 279-288. 
Arab Univ. J. Agric. Sci., Ain Shams Univ., Cairo, Egypt

28(2), 367-382, 2020

Website: http://ajs.journals.ekb.eq

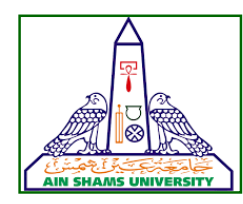

382

\title{
AN ECONOMIC STUDY ON TOMATOES EXPORT COMPETITIVENESS IN EGYPT
}

\author{
Elkhishin* E.A. \\ Higher Institute for Agricultural Cooperation, Cairo, Egypt \\ *Corresponding author: elkhishinss@gmail.com
}

Received 15 April, 2020

Accepted 16 August, 2020

\begin{abstract}
Vegetables export in general and tomatoes crop in particular are facing serious challenges in Egypt with regards to declining competitiveness in global markets in addition to some other challenges related to the ability to penetrate global markets and the variation in prices for different importing countries. This is in addition to the variation in demand conditions in importing markets. Through reviewing the competitiveness indicators for this crop in global markets. The paper aims at exploring tools to enhance the exports of Tomatoes crop through investigating the core competitiveness indicators shows that the quantity and value of tomato exports was highly fluctuating during the period under investigation. The lowest value was recorded in 2000 and amounted to 1.7 thousand tons. The maximum value was recorded in 2013 and amounted 74.8 thousand tons. Since then. The variable showed high fluctuation until 2018 where the quantity exported reached 41.8 thousand tons. The exporting value also was fluctuating. It reached its lowest in 2000 and amounted to 454 thousand dollars while the maximum reached around 728.7 thousand in 2015. The value decreased to 488.6 thousand in 2018 while the tomato exports also fluctuated since
\end{abstract}

2000 till 2007 and reached its maximum in 2017 with around $\$ 1513$ /tons. The value showed a fluctuating trend where it reached around $\$ 1169 /$ ton. The Saudi market dominated the market with around $37.16 \%$ of total Egyptian tomatoes exports. Whether fresh or frozen. The paper also shows there is clear export competitiveness in global markets. The average index value reached around 1.33. Which means that this crop is one of the very important crops that efficiently competes in the global markets. The paper finally shows the penetration parameter is weak and that there is minimal increase in this indicator. This means that there is a possibility to increase exported quantities from tomatoes through studying the reasons behind the fluctuations and design some policies and export mechanisms that can improve export competitiveness and penetration rates. The paper recommends working on minimizing the fluctuation in the penetration coefficient for Tomatoes exports in Saudi and UK markets since such markets have the capacity to absorb more Egyptian tomatoes exports.

Keywords: Export Competitiveness; Egyptian tomatoes; Coefficient of apparent comparative advantage; Saudi Market 